\title{
Discrete-element modelling of rock communition in a cone crusher using a bonded particle model
}

\author{
H. LI*, G. MCDOWELL* and I. LOWNDES*
}

\begin{abstract}
It is known that discrete-element method (DEM) modelling of rock size reduction can be achieved using two approaches - the population balance model (PBM) and the bonded particle model (BPM). However, only the PBM has been successfully used in DEM modelling of a cone crusher in the literature. The aim of this paper is to explore the feasibility of using the BPM to represent the size reduction of rock experienced within a cone crusher chamber. The feed rock particles were represented by isotropic dense random packing agglomerates. The simulation results were compared with the PBM simulation results and it was shown that the BPM cone crusher model was able to satisfactorily replicate the performance of a cone crusher and can provide a more accurate prediction of the percentage of fine products. In addition, the novel contribution of this work is that the rock feed material comprised particles of realistic shapes that break into more realistically shaped fragments compared with the fragments with defined shapes in the PBM.
\end{abstract}

KEYWORDS: discrete-element modelling; dynamics; failure; mining; particle crushing/crushability; rocks/rock mechanics

ICE Publishing: all rights reserved

\section{NOTATION}

\begin{tabular}{|c|c|}
\hline$B_{\mathrm{o}}$ & bond strength \\
\hline$M$ & $\begin{array}{l}\text { cumulative mass of all the micro-spheres included in } \\
\text { a fragment }\end{array}$ \\
\hline$P$ & porosity of the initial agglomerate \\
\hline$R_{\mathrm{f}}$ & equivalent radius of the fragment \\
\hline & density of micro-spheres included in the fragment \\
\hline
\end{tabular}

\section{INTRODUCTION}

Cone crushers are the most common type of mineral comminution machine and are used widely in the minerals and aggregates extractive industries to crush medium or above medium sized rocks. The use of an incremental build and the testing of alternative design prototypes are expensive, often requiring the production of several models to identify the required economic improvement in crusher performance. The development of a validated computational simulation model of a cone crusher could significantly reduce the required lead time and costs.

The discrete-element method (DEM) (Cundall \& Strack, 1979) provides a potential method to investigate the mechanical behaviour of the flow and breakage of granular material at both micro and macro scales. The population balance model (PBM) approach replaces the predicted failed parent particle by a number of new and smaller fragments while the bonded particle model (BPM) approach represents individual particles as an assembly of bonded micro-spheres, with breakage simulated by the failure of some of the bonds. The PBM (Herbst et al., 2003) has already successfully been applied in DEM modelling cone crusher performance (Lichter et al., 2009; Li et al.,

Manuscript received 28 January 2014; first decision 11 March 2014; accepted 21 April 2014.

Published online at www.geotechniqueletters.com on 20 May 2014.

*Faculty of Engineering, University of Nottingham, Nottingham, UK
2014). However, as the progeny fragments have to be formed and located at the position of the parent particle, the PBM approach cannot replicate the movement of the original parent and the subsequent progeny particles formed post-failure. In contrast, the BPM can consider particle movement as a result of a crushing sequence as the agglomerate is directly broken into smaller particles.

The research results presented in this paper explore the feasibility of using the BPM to simulate the performance of a cone crusher using the DEM. The feed rock particles are represented by a collection of dense randomly packed agglomerates of bonded micro-spheres and the simulation results are compared with the PBM simulation results reported by Li et al. (2014).

\section{CONSTRUCTION OF DEM CONE CRUSHER MODEL}

The program PFC3D (Itasca, 2008) and the prototype cone crusher constructed by Li et al. (2014) were used in this study. Figures 1 and 2 illustrate typical vertical and horizontal cross-sectional views through a typical cone crusher. Table 1 shows the scale of the prototype cone crusher and the corresponding parameters are illustrated in Fig. 1. The reader is referred to the work of $\mathrm{Li}$ et al. (2014) for further details of the geometry of the cone crusher. Figure 3 shows an illustration of the representative threedimensional (3D) rendered surfaces of the mantle and concaves formed within a typical DEM cone crusher model.

\section{AGGLOMERATE CALIBRATION}

Various types of agglomerates have been used for DEM modelling of particle breakage, for example hexagonal closed packing agglomerates (Cheng et al., 2003; Lim, 2004; Lim \& McDowell, 2007), agglomerates generated by the radius expansion method (Potyondy \& Cundall, 2004; Cil \& Alshibli, 2012) and dense random packing agglomerates ( $\mathrm{Li}$ et al., 2013). As a dense and isotropic particle 


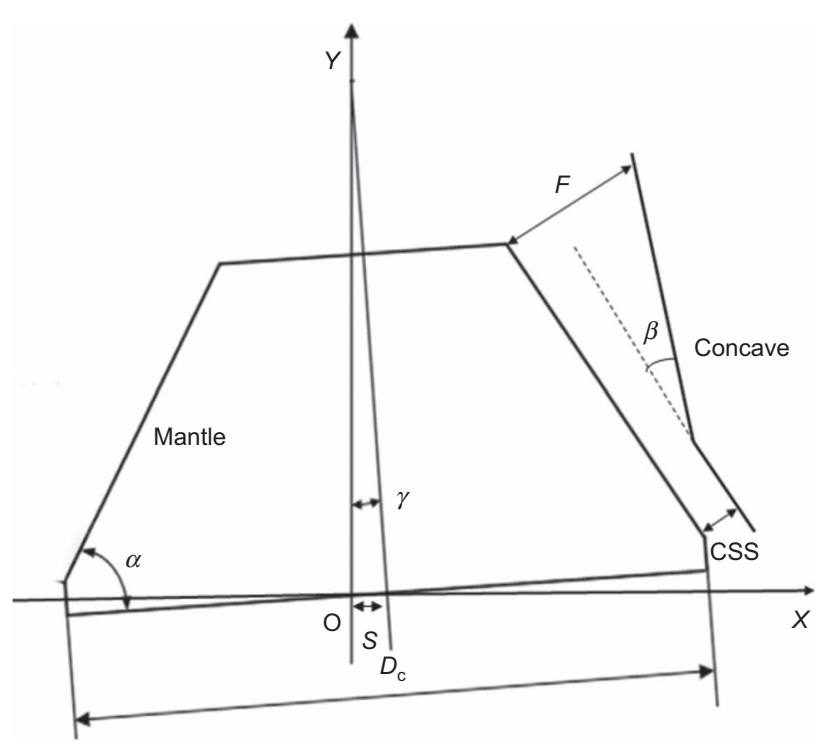

Fig. 1. Vertical cross-section view through a typical cone crusher

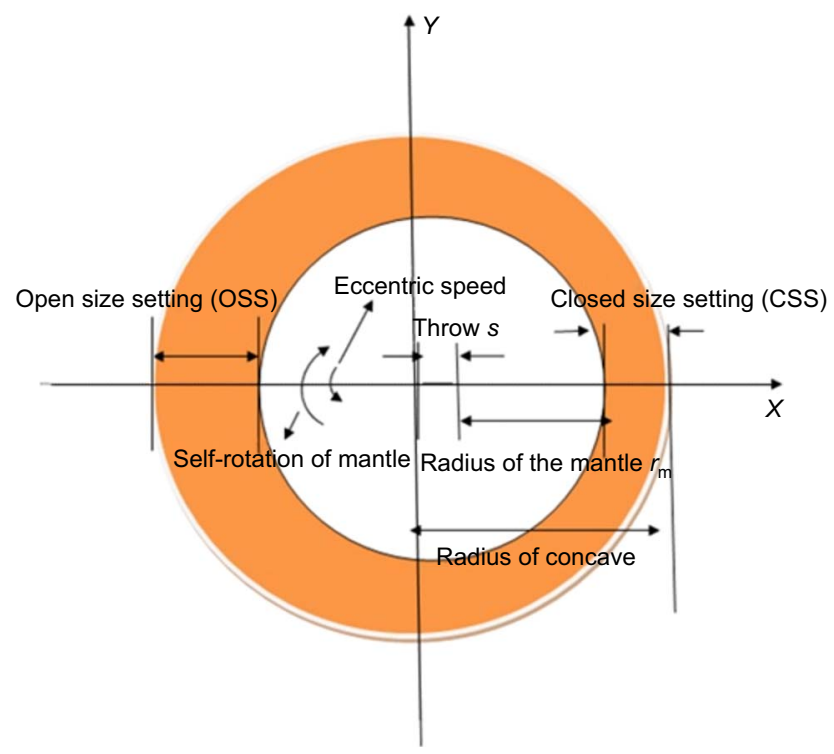

Fig. 2. Horizontal cross-section view through a typical cone crusher

system is desired, the dense random agglomerate generated by Li et al. (2013) was used in this study; this is achieved by inserting particles to fill voids in the agglomerate (further details on the generation are given by $\mathrm{Li}$ et al. (2013)).

Li et al. (2014) diametrically crushed granite ballast particles of three sieve size fractions and found that, for each size fraction, the tensile strengths of 30 particles followed the Weibull distribution (Weibull, 1951). The tensile strengths were then used as the breakage criterion in their PBM of cone crusher performance. In order to make a

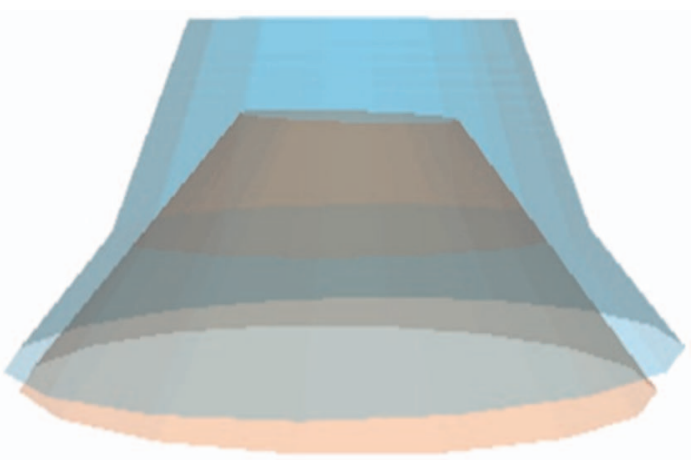

Fig. 3. DEM cone crusher model

comparison with the PBM simulation results of Li et al. (2014), the agglomerates used here were calibrated to have the same tensile strength distribution as the granite ballast particles crushed in the diametrical compression tests of Li et al. (2014). The spherical dense random packing agglomerate used here is an isotropic particle ( $\mathrm{Li}$ et al., 2013); in this case it is expected that the strength of the agglomerate is proportional to the bond strength (Cil et al., 2013; Li, 2013).Thus, modelling of the variation of particle strengths can be achieved by simply giving each agglomerate a single value of bond strength, taken from the relevant distribution of the experimental results. The calibration process was as follows.

- The Young's modulus was chosen with a Poisson's ratio of $0 \cdot 2$ to give an initial elastic response that matched the experiments.

- The agglomerate was given a random bond strength, assuming a Weibull modulus equal to that for the Weibull distribution of particle strengths in the experiments.

- This agglomerate was then crushed to obtain its strength $\sigma$.

- The bond strength was then scaled by $\sigma / \sigma_{\mathrm{o}}$ to obtain the assumed $37 \%$ bond strength $B_{\mathrm{o}}$.

- The agglomerates were then assumed to have a bond strength given by a Weibull distribution with the chosen value of $m$ and a $37 \%$ bond strength $B_{\mathrm{o}}$.

In a discussion of the work of Cil \& Alshibli (2012),

McDowell \& Li showed that the crushed agglomerates had approximately the same distribution of strengths as the assumed bond strength distribution if the average bond strength was scaled to give the correct average agglomerate strength (the reader is referred to Fig. 6 of that discussion paper (Cil et al., 2013)). The calibrated micro input parameters are shown in Table 2 and further explanation of the definitions of the parameters is given in Itasca (2008).

\section{SIMULATION PROCEDURE}

The DEM simulation models used 100 particles as the feed material. The sizes of the particles were chosen to be in the range 14-28 $\mathrm{mm}$, which was the smallest size fraction of the ballast particles crushed experimentally (to save computational time). The number of spheres in each agglomerate ranged from 1328 to 1512 and the total number of spheres forming the 100 particles was 141368 . The particle shape

Table 1. Parameters used to construct the DEM cone crusher model

\begin{tabular}{l|c|c|c|c|c|c|c}
\hline$F: \mathrm{mm}$ & CSS: $\mathrm{mm}$ & $s: \mathrm{mm}$ & $\alpha:$ degrees & $\beta$ : degrees & $\gamma:$ degrees & $\Delta L: \mathrm{mm}$ & $D_{\mathrm{c}}: \mathrm{mm}$ \\
\hline 55 & $12-18$ & $4 \cdot 5$ & 45 & $18-22$ & 2 & 50 & 300 \\
\hline
\end{tabular}



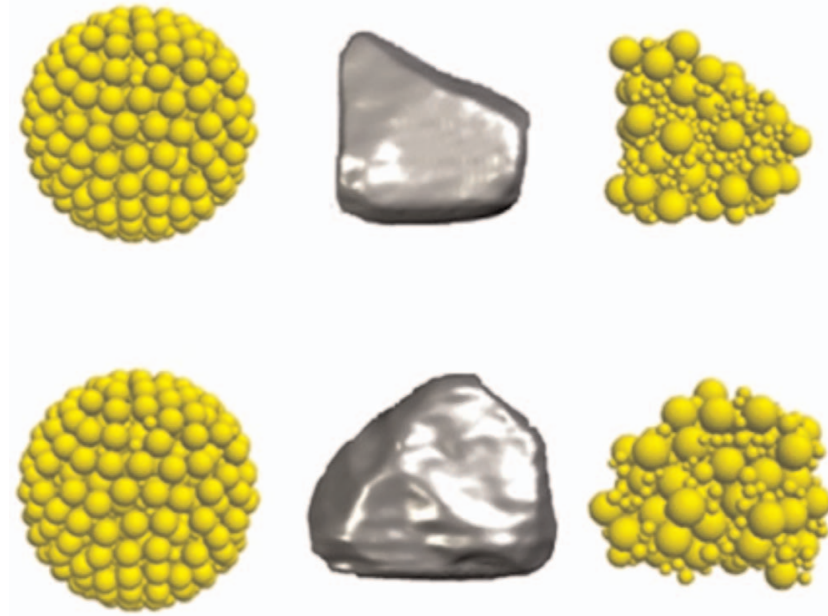

Fig. 4. Modelling procedure used to generate irregular particle shapes

was also considered and this is a unique feature of the approach presented in this paper. Figure 4 illustrates the modelling stages used to generate the irregular agglomerate shapes, as follows.

- Generate a spherical random dense packing agglomerate of radius ratio 4 (the ratio of the radii of the largest and smallest spheres in the agglomerate); a radius ratio of 4 is the lowest ratio required to generate a dense isotropic particle using the void filling method proposed by $\mathrm{Li}$ et al. (2013). The radius of the agglomerate should be at least equal to the measured sieve size of the real particle.

- Calculate the 3D external profile of the real particle; the tool used in this work was a 3D laser digitiser.

- Check the centres of all the spheres in the agglomerate to reject the spheres whose centres lie outside the boundary.

The simulation procedure is shown in Fig. 5, which depicts animation stills of the sequential stages of the solution of the model. The procedure was as follows.

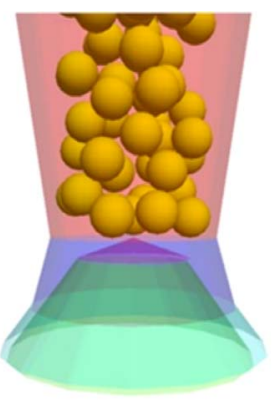

(a)

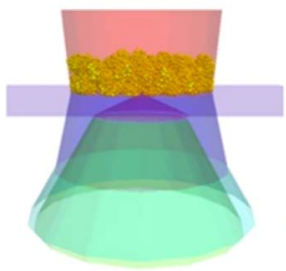

(c)

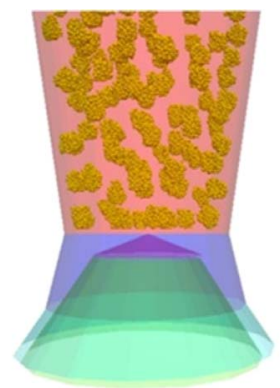

(b)

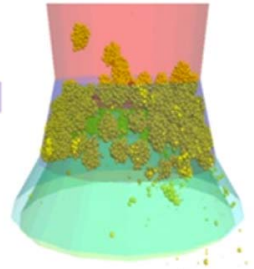

(d)

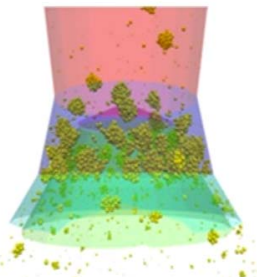

(e)
Fig. 5. Snapshots of the crusher simulation in action using BPM approach

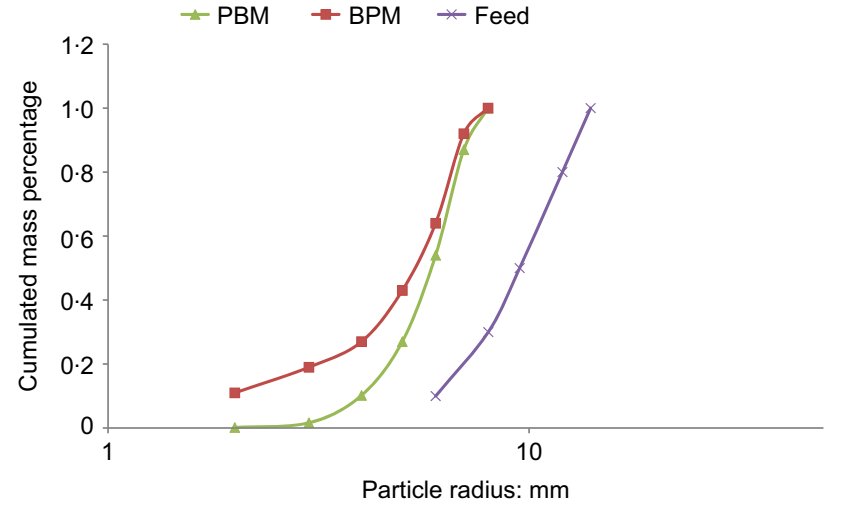

Fig. 6. Comparison of BPM cone crusher and PBM cone crusher

- 100 particles of radius $28 \mathrm{~mm}$ were randomly generated inside the artificial cylinder wall above the mantle (Fig. 5(a)).

- The spheres are replaced by agglomerates (Fig. 5(b)).

- The agglomerates are deposited into the feed bin by gravity. The bonds of the agglomerates are given an artificially high bond strength to avoid breakage during the deposition process. A flat artificial wall is constructed above the concave to avoid particles dropping into the chamber directly (Fig. 5(c)).

- The bonds in the agglomerates are re-allocated their normal values. The flat artificial wall is then deleted to allow the particles to flow into the chamber (Fig. 5(d)).

- The mantle is rotated (Figs 5(d) and 5(e)).

\section{RESULTS}

The sizes of the fragments were calculated as the equivalent radius, expressed as

$$
R_{\mathrm{f}}=\left(\frac{3 M}{4 \pi \rho(1-P)}\right)^{1 / 3}
$$

where $R_{\mathrm{f}}$ represents the equivalent radius of the fragment, $M$ denotes the cumulative mass of all the spheres included in the fragment, $\rho$ is the density of micro-spheres $(2700 \mathrm{~kg} /$ $\mathrm{m}^{3}$ as shown in Table 2 ) and $P$ is the porosity of the initial agglomerate, which is $0 \cdot 31$ (Li et al., 2013).

The stills in Fig. 5 show that some fragments are projected upwards out of the crusher chamber or bin. This dynamic phenomenon is caused by particle collisions and may also occur in the operation of real cone crushers. Figure 6 shows a graphical comparison of the predicted cumulative product size distributions for the two breakage models using the same cone crusher model geometry and operational conditions. The PBM curve is replotted based

Table 2. Input values of micro parameters of the agglomerate used in BPM DEM cone crusher mode

\begin{tabular}{l|l}
\hline Parameter & Value \\
\hline Micro-sphere radius: $\mathrm{m}$ & $0 \cdot 0025$ \\
Micro-sphere density: $\mathrm{kg} / \mathrm{m}^{3}$ & 2700 \\
Friction coefficient & $0 \cdot 5$ \\
Young's modulus: GPa & 70 \\
Poisson's ratio & $0 \cdot 2$ \\
Parallel bond radius multiplier & 1 \\
Parallel bond normal stiffness: N/m & $5 \times 10^{12}$ \\
Parallel bond shear stiffness: N/m & $2 \times 10^{12}$ \\
$37 \%$ normal/shear bond strength, $B_{\mathrm{o}}: \mathrm{MPa}$ & 60 \\
\hline
\end{tabular}




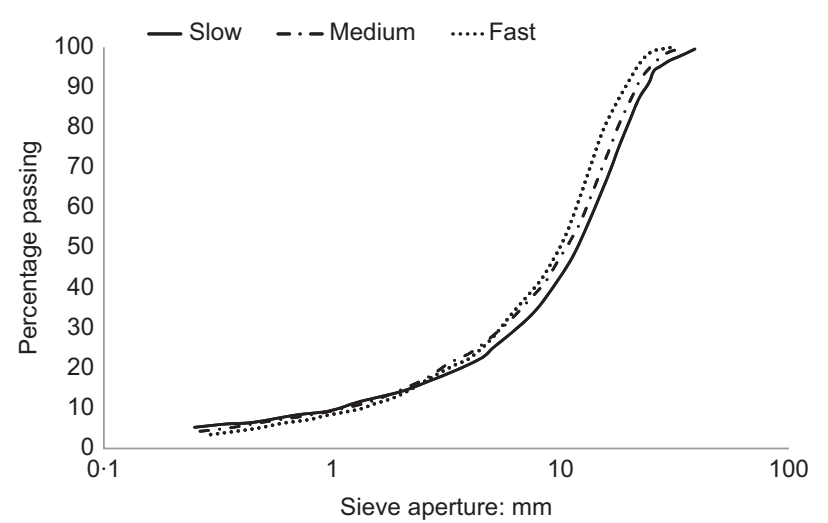

Fig. 7. Traditional product curve of cone crusher (adapted from Hulthen (2010))

on the simulation results of Li et al. (2014), for the same cone crusher geometry, the same eccentric speed and the same particle strengths. The closed size setting (CSS) and eccentric speed were $15 \mathrm{~mm}$ and $300 \mathrm{rpm}$, respectively. Examination of the data presented in Figure 6 shows that, for any sieve size, the cumulative mass percentage produced by the BPM is always higher than that computed by the PBM. The largest differences between the predicted solutions occur at the finest size $(2 \mathrm{~mm})$. The cumulative mass of products finer than $2 \mathrm{~mm}$ for the BPM and PBM are 9.8 and $0.5 \%$, and this makes the BPM curve more consistent with a traditional product curve of a cone crusher. Figure 7 (Hulthen, 2010) shows examples of product curves of cone crushers of various eccentric speeds in the industry. The difference between the predicted distributions decreases for the largest particles sizes.

It should be noted that the simulation of the crushing of the agglomerate feed in the cone crusher took $150 \mathrm{~d}$ on a PC with a specification of Intel Core2 Q9650 up to $3.0 \mathrm{GHz}$. The BPM method is therefore seen to be computationally very time consuming - the equivalent simulation using the PBM particle replacement method only took up to $20 \mathrm{~d}$. However, the purpose of this paper was a feasibility study to establish whether it is possible to model the crushing of particles of realistic shapes in a cone crusher and this was found to be possible and to give realistic results. This makes it possible to run simulations with different feeds and models and crusher geometries to establish which parameters can be adjusted to increase comminution efficiency and therefore inform the design of new prototypes.

\section{CONCLUSIONS}

A prototype DEM cone crusher model has been successfully constructed using the bonded particle model (BPM). The feed particles were represented by dense random packing agglomerates. The agglomerates were calibrated to have the same tensile strength distribution as experimental diametrically crushed granite ballast particles. A comparison with population balance model (PBM) simulation results reported in the literature shows that the BPM cone crusher model was able to satisfactorily replicate the performance of a cone crusher. It is thus feasible to model rock breakage in a comminution machine with an eccentrically rotating cone using alternative and complementary methods, and modelling the fracture of irregularly shaped particles using agglomerates of bonded particles has been shown to be possible. Based on the fact that the BPM considers the particle flow as a result of the crushing sequence and provides more accurate results for fine products, it is very useful even it consumes more computation time than the PBM.

\section{REFERENCES}

Cheng, Y. P., Nakata, Y. \& Bolton, M. D. (2003). Discrete element simulation of crushable soil. Géotechnique 53, No. 7, 633-641.

Cil, M. B. \& Alshibli, K. A. (2012). 3D assessment of fracture of sand particles using discrete element method. Géotech. Lett. 2, No. 2, 161-166.

Cil, M. B., Alshibli, K. A., McDowell, G. R. \& Li, H. (2013). Discussion: 3D assessment of fracture of sand particles using discrete element method. Géotech. Lett. 3, No. 3, 13-15.

Cundall, P. \& Strack, O. (1979). A discrete numerical model for granular assemblies. Géotechnique 29, No. 1, 47-65.

Herbst, J. A., Lo, Y. C. \& Flintoff, B. (2003). Size reduction and liberation. In Principles of mineral processing (Fuerstenau, M. C., \& Han, K. N. (eds.)). Littleton, CO: Society of Mining, Metallurgy and Exploration, pp. 61-118.

Hulthen, E. (2010). Real-time optimization of cone crushers. PhD thesis, Chalmers University of Technology.

Itasca (2008). PFC3D (particle flow code in three dimensions), version 3.0. Minneapolis, MN: Itasca Consulting Group.

Li, H. (2013). Discrete element method modelling rock flow and breakage within a cone crusher. $\mathrm{PhD}$ thesis, University of Nottingham.

Li, H., McDowell, G. R. \& Lowndes, I. (2013). Discrete element modelling of rock breakage using dense random packing agglomerates. Géotech. Lett. 3, No. 3, 98-102.

Li, H., McDowell, G. R. \& Lowndes, I. (2014). Discrete element modelling of a rock comminution machine. Powder Technol. (accepted).

Lichter, J., Lim, K., Potapov, A. \& Kaja, D. (2009). New developments in cone crusher performance optimization. Miner. Engng 22, No. 7, 613-617.

Lim, W. L. (2004). Mechanics of railway ballast behaviour. PhD thesis, University of Nottingham.

Lim, W. L. \& McDowell, G. R. (2007). The importance of coordination number in using agglomerates to simulate crushable particles in the discrete element method. Géotechnique 57, No. 8, 701-705.

Potyondy, D. O. \& Cundall, P. A. (2004). A bonded-particle model for rock. Int. J. Rock Mech. Mining Sci. 41, No. 8, 1329-1364.

Weibull, W. (1951). A statistical distribution function of wide applicability. J. Appl. Mech. 18, No. 18, 293-297.

\section{WHAT DO YOU THINK?}

To discuss this paper, please email up to 500 words to the editor at journals@ice.org.uk. Your contribution will be forwarded to the author(s) for a reply and, if considered appropriate by the editorial panel, will be published as a discussion. 